\title{
КЛАСТЕРНАЯ ОЦЕНКА ВЗАИМОСВЯЗИ СОЦИАЛЬНОЙ ЗАЩИТЫ И ЭКОНОМИЧЕСКОГО РАЗВИТИЯ В АДМИНИСТРАТИВНО- ТЕРРИТОРИАЛЬНЫХ ОБРАЗОВАНИЯХ РЕСПУБЛИКИ КАЗАХСТАН
}

\author{
(C) 2021 Валиева Елизавета Николаевна \\ доктор экономических наук, профессор, профессор кафедры финансов и кредита \\ Самарский государственный экономический университет, Россия, Самара \\ E-mail: rad8063@yandex.ru \\ (c) 2021 Машанова Самал Амангельдиевна \\ старший преподаватель кафедры «Экономика и менеджмент» \\ Западно-Казахстанский инновационно-технологический университет, Республика Казахстан, \\ Уральск \\ E-mail: samal.kz.79@mail.ru
}

\section{(c) 2021 Проскурина Наталья Вячеславовна}

кандидат экономических наук, доцент, доцент кафедры статистики и эконометрики

Самарский государственный экономический университет, Россия, Самара

E-mail: nvpros@mail.ru

Качественная оценка процесса реформирования социально-экономических институтов в Республике Казахстан, в том числе предполагает выявление однородных по уровню социальной защиты территорий, а также факторов его определяющих. Данная проблематика недостаточно представлена в научных источниках. Имеющиеся публикации в основном посвящены этапам институционального строительства социальной защиты [2], также особенностям организации отдельных видов социального страхования, обеспечения и помощи [3,6]. Объект исследования - социальная защита в административно-территориальных образованиях (АТО) Республики Казахстан первого уровня. Предмет исследования - взаимосвязь между результативностью социальной защиты и развитием экономики в АТО. Теоретической основой работы является концепция социального рыночного хозяйства А. Мюллера- Армака [4]. В анализе используется метод кластерного анализа к-средних. Полученные результаты послужат экономическому обоснованию управленческих решений, направленных на развитие системы социальной защиты населения в Казахстане.

Ключевые слова: социальная защита, кластерный анализ, группировка административно- территориальных образований Казахстана.

В первые годы рыночных преобразований В Республике Казахстан (РК) система социальной защиты характеризовалась несистемностью законодательства и недостаточными стимулами к участию в ней лиц, состоящих в отношениях по найму. Преобладал принцип солидарности с высоким уровнем государственного участия и отсутствием самоответственности людей за периоды нетрудоспособности, при этом значительные объемы финансовых ресурсов на материальную поддержку нетрудоспособных членов общества направляются из республиканского бюджета. В 1994 году РК совместно с другими членами СНГ утвердил Хартию социальных прав и гарантий граждан независимых государств, таким образом, заявил о своей приверженности основным принципам ее деятельности, в первую очередь принципу социального партнерства.

В рамках развития «Концепции социальной защиты населения Республики Казахстан» (2001 г.) принимается Закон «Об обязательном социальном страховании» (2003 г.), который заложил институциональные основы страхового механизма финансирования социальной защиты. Государственный Фонд социального страхования был создан в 2004 году как акционерное общество, принадлежащее государству и выполняющее функции, связанные с защитой работающего населения при наступлении социальных рисков. Он занимает центральное место в системе социального страхования. В развитие последней в 2005 году в Казахстане введен в действие 
Закон «Об обязательном страховании работника от несчастных случаев при исполнении им трудовых (служебных) обязанностей».

Концепцией социальной защиты населения предусматривалось развитие обязательного накопительного пенсионного страхования, в том числе повышение ответственности плательщиков взносов и совершенствования механизма пенсионных выплат из накопительных пенсионных фондов. В 2013 г. принимается 3акон «О пенсионном обеспечении в Республике Казахстан», в соответствии с которым создается Единый накопительный пенсионный фонд (ЕНПФ), которому были переданы пенсионные активы частных накопительных пенсионных фондов. В 2018 г. в пенсионную систему вводится условно-накопительная компонента, которая предполагает, что работодатели за счет собственных средств перечисляют 5\% от размера дохода работника в ЕНПФ.

В 2018 году в республике Казахстан приступили к реализации закона «Об обязательном социальном медицинском страховании» (2015 г.). В течение 2018 и 2019 годов принято решение осуществлять только ежемесячные отчисления работодателей в Фонд социального медицинского страхования в размере $1,5 \%$ от заработной платы каждого работника, с 2020 года - 2\%. Эта норма также распространяется на индивидуальных предпринимателей и владельцев крестьянских хозяйств, нанимающих работников. Актуальность новых законодательных актов обусловлена хроническим недофинансированием бесплатной медицинской помощи [7].

Сформированная система социального страхования позволяет отнести РК к либеральным социальным государствам, в которых социальные выплаты обусловлены вкладом застрахованного в формирование страхового фонда. Гипотетически в этом случае результативность социальной защиты во многом определяется экономическим развитием, от которого зависят занятость, оплата труда, а, следовательно, страховые взносы и выплаты. В тоже время имеются исследования, свидетельствующие об отсутствии выраженной зависимости между уровнями экономического развития государства и социальной защиты [5].

Для доказательства или опровержения гипотезы была поставлена задача разбить административно-территориальные образования (ATO) РК на три группы с низким, средним и высоким уровнем социальной защиты (экономического развития) методом кластерного анализа к-средних. Использовался ППП Statistika 13.3.

Исходная совокупность факторов, характеризующих уровень социальной защиты территорий, была представлена 12 показателями за 2020 год. После проверки факторов на мультиколлинеарность были отобраны статистически независимые индикаторы: отчисления в Государственный фонд обязательного социального страхования на одного застрахованного, обязательные пенсионные накопления на одного застрахованного, среднее пособие по социальному страхованию, средний размер социальной помощи, количество бедных, коэффициент смертности.

Для кластеризации АТО РК по уровню экономического развития были выбраны 11 факторов за 2020 год. В результате проверки на мультиколлинеарность были отобраны: ВРП на душу населения, темп роста инвестиций в основной капитал, темп роста строительно-монтажных работ, индекс потребительских цен, объем сельхозпроизводства на душу населения, уровень безработицы.

Результаты проведенного дисперсионного анализа свидетельствуют о том, что разбиение совокупности на 3 кластера вполне обосновано, так как внутригрупповые, отличны друг от друга; p - значение каждого фактора не превышает заданные уровень значимости, равный $5 \%$. Таким образом, проведенная кластеризация является эффективной и достоверной [1].

На рисунке 1 представлен график средних нормированных значений показателей, характеризующих уровень социальной защиты в кластерах.

Второй кластер имеет наилучшие значения практически всех факторных показателей, что свидетельствует о сравнительно высоком уровне социальной защиты в муниципалитетах, попавших в данный кластер. В первом кластере наблюдаются самые низкие значения факторных показателей, что позволяет сделать вывод об относительно низком уровне компенсации социальных рисков имеющимися институтами социальной защиты в этой группе муниципалитетов. K третьему кластеру принадлежат территории, занимающие промежуточное положение между муниципалитетами второго и первого кластеров. Причем, средние нормированные значения 
График средних для кажд. кл.

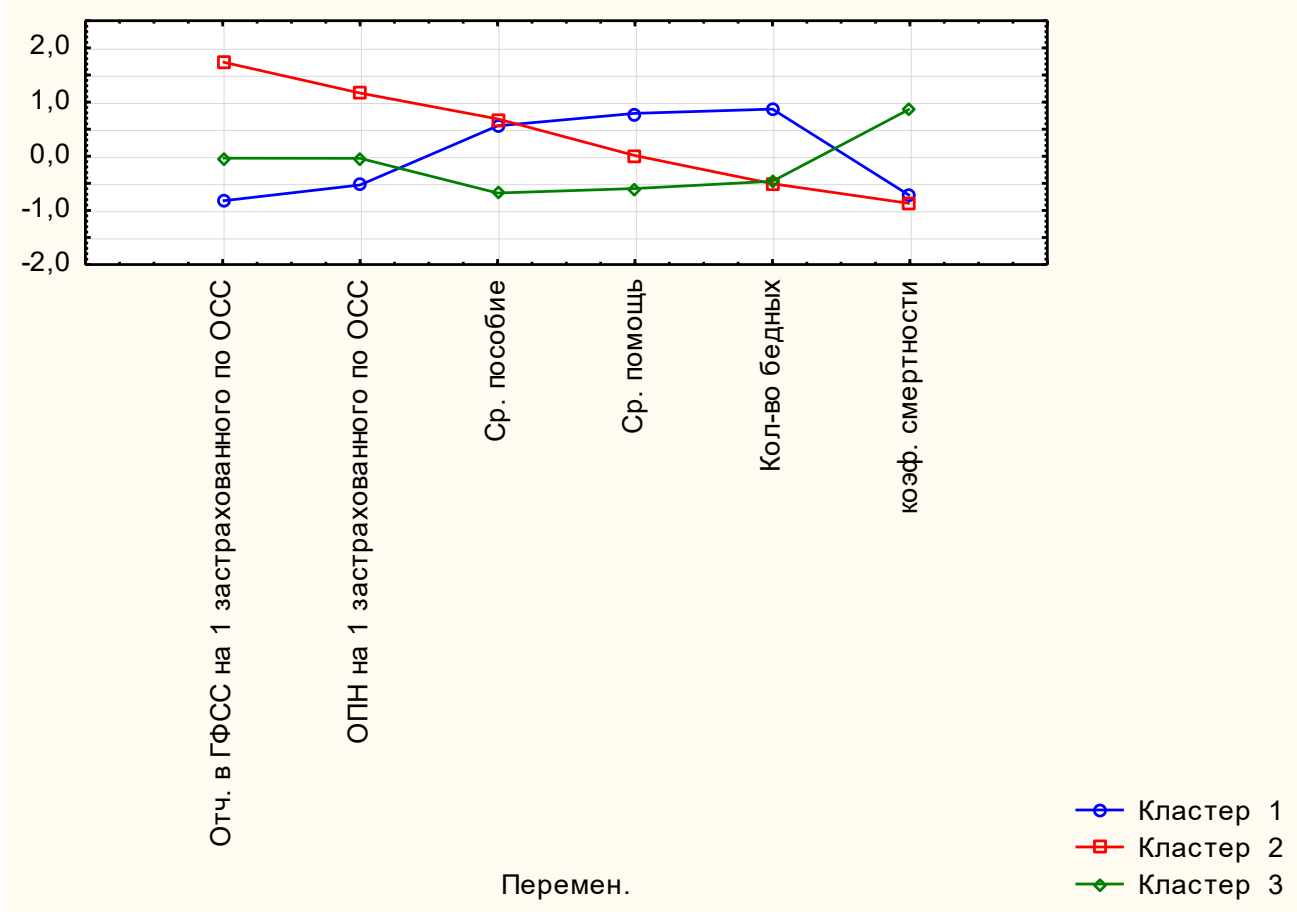

Рисунок 1. График средних нормированных значений показателей, характеризующих уровень социальной защиты в кластерах

факторных показателей для данного кластера позволяют сделать вывод о большей близости соответствующих муниципалитетов к первому кластеру, то есть уровень социальной защиты населения в нем скорее низкий, чем средний.

На рисунке 2 представлен график средних нормированных значений показателей, характеризующих уровень экономического развития в кластерах.

Во второй кластер (высокий уровень экономического развития) вошли территории с развитой добывающей промышленностью (Атырауская и Мангистауская области), машиностроением (г. Алматы), сферой услуг (г. НурСултан). Достаточно близко к данному кластеру находятся муниципалитеты, принадлежащие к третьему кластеру, Туркестанская область и г. Шымкент (средний уровень экономического развития). Высокие темпы роста капитального строительства позволяют им занять достойное место в республике по уровню экономического развития. К сожалению, 60\% АТО Казахстана являются территориями с низким уровнем экономического развития (первый кластер). Основным видами экономической деятельности здесь является сельское хозяйство и в меньшей степени пищевая промышленность. Состав каждого кластера представлен в таблице 2.

С целью решения поставленной аналитической задачи на основании полученных кластеров на первом этапе создадим следующие группы административно-территориальных об-

Таблица 1. Состав кластеров АТО Республики Казахстан по уровню социальной защиты населения в 2020 г.

\begin{tabular}{|c|c|c|}
\hline 1 кластер (6 АТО) & 2 кластер (3 АТО) & 3 кластер (8 АТО) \\
\hline Низкий уровень & Высокий уровень & Средний уровень \\
\hline Алматинская & Атырауская & Акмолинская \\
Жамбылская & Мангистауская & Актюбинская \\
Кызылординская & г. Алматы & Западно-Казахстанская \\
Туркестанская & & Карагандинская \\
г. Нур-Султан & & Костанайская \\
г. Шымкент & & Павлодарская \\
& & Северо-Казахстанская \\
& & Восточно-Казахстанская \\
\hline
\end{tabular}


График средних для кажд. кл.

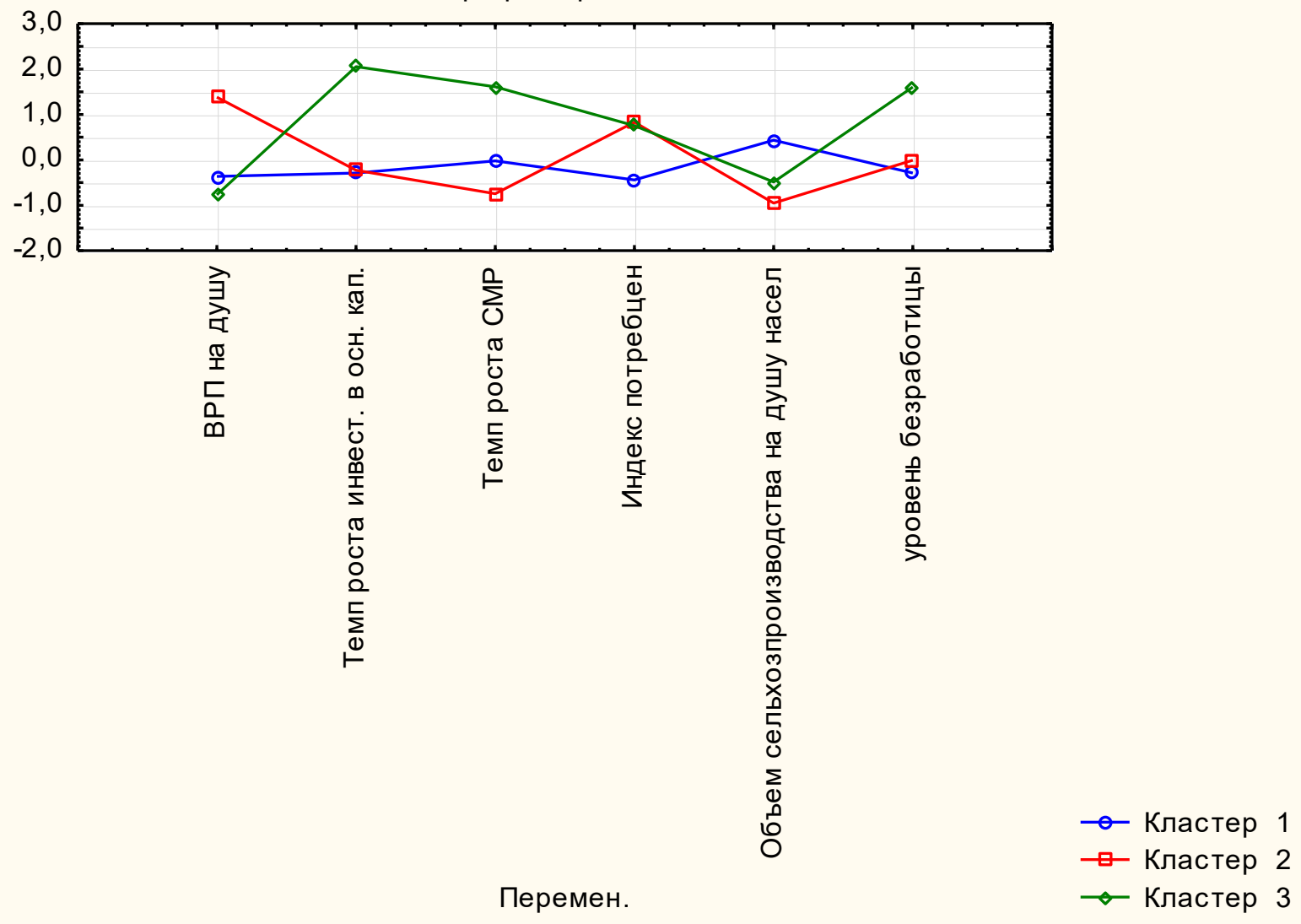

Рисунок 2. График средних нормированных значений показателей, характеризующих уровень экономического развития в кластерах

Таблица 2. Состав кластеров АТО Республики Казахстан по уровню экономического развития в 2020 г.

\begin{tabular}{|c|c|c|}
\hline 1 кластер (11 АТО) & 2 кластер (4 АТО) & 3 кластер (2 АТО) \\
\hline Низкий уровень & Высокий уровень & Средний уровень \\
\hline Акмолинская & Атырауская & Г. Шымкент \\
Актюбинская & Мангистауская \\
Алматинская & г. Нур-Султан \\
Западно-Казахстанская & г. Алматы & \\
Жамбылская & & \\
Карагандинская & & \\
Костанайская & & \\
Кызылординская & & \\
Павлодарская & & \\
Северо-Казахстанская & & \\
Восточно-Казахстанская & & \\
\hline
\end{tabular}


разований Республики Казахстан:

- удовлетворительный уровень социальной защиты населения;

- удовлетворительный уровень экономического развития;

- низкий уровень социальной защиты населения;

- низкий уровень экономического развития.

На втором этапе сопоставим состав группы с удовлетворительным (низким) уровнем экономического развития с составом группы с удовлетворительным (низким) уровнем социальной защиты населения. Результаты представлены в таблице 3.

В $82 \%$ наблюдается соответствие уровней развития экономики и социальной защиты. Исключениями являются Туркестанская область, г. Нур-Султан и г. Шымкент. Вероятно, попадание столицы республики в группу с низким уровнем социальной защиты можно объяснить демографическим составом (относительно молодым) населения, что сокращает потребность в социальных выплатах. Туркестанская область создана 19.06.2018 г. в результате преобразования Южно-Казахстанской области, тогда же быв- ший административный центр - г. Шымкент стал городом республиканского значения. Центром Туркестанской области стал город Туркестан. Территории включены в Государственную программу индустриально-инновационного развития. Экономическое развитие в регионе сконцентрировано на развитии малого и среднего бизнеса, привлечении инвестиций, увеличении объемов экспорта и туризме. Обладая логистическими преимуществами (автомагистраль «Западная Европа - Западный Китай»), регион имеет недостаточно развитый человеческий капитал, а также невысокий размер оплаты труда. Последнее обстоятельство и определило попадание территорий в группу муниципалитетов с низким уровнем социальной защиты населения, так как величина пенсионных и социальных выплат напрямую зависит от размера оплаты труда.

Таким образом, гипотезу о прямой зависимости между уровнем экономического развития и уровнем социальной защиты населения в АТО PK и о либеральном характере социальной рыночной экономики республики можно считать подтвержденной.

Таблица 3. АТО РК с удовлетворительным и низким уровнями экономического развития и социальной защиты населения

\begin{tabular}{|c|c|}
\hline $\begin{array}{c}\text { Муниципалитеты с удовлетворительным уровнем } \\
\text { экономического развития }\end{array}$ & $\begin{array}{l}\text { Муниципалитеты с удовлетворительным уровнем } \\
\text { социальной защиты населения }\end{array}$ \\
\hline Атырауская & Атырауская \\
г. Алматы & г. Алматы \\
Мангистауская & Мангистауская \\
г. Нур-Султан & \\
Туркестанская & \\
г. Шымкент & Акмолинская \\
Муниципалитеты с низким уровнем экономического & Ауниципалитеты с низким уровнем социальной \\
развития & Аащиты населения \\
\hline \multicolumn{1}{|c|}{ Алатинская } \\
Акмолинская & Восточно-Казахстанская \\
Алматинская & Жамбылская \\
Восточно-Казахстанская & Западно-Казахстанская \\
Жамбылская & Карагандинская \\
Западн-Казахстанская & Костанайская \\
Карагандинская & Кызылординская \\
Костанайская & Павлодарская \\
Кызылординская & Северо-Казахстанская \\
Павлодарская & г. Нур-Султан \\
Северо-Казахстанская & Туркестанская \\
& г. Шымкент \\
\hline
\end{tabular}




\section{Библиографический список}

1. Дюран Б. и Оделл П. Кластерный анализ. Пер. с англ. Е. 3. Демиденко. Под ред. А. Я. Боярского. Предисловие А.Я.Боярского. М., «Статистика», 1977, 128 с.

2. Жусипов Б.С. Социальная защита в контексте социальной политики Республики Казахстан социальная работа в современном мире: взаимодействие науки, образования и практики.- Материалы VII международной научно-практической конференции. - Издательский дом «Белгород».- Белгород. - 2015 г. https:// elibrary.ru/item.asp?id=26797027

3. Кожахметова А.А. О механизме социальной защиты населения в Республике Казахстан // Эпоха науки, № 18.- 2019.-c. 18-22 https://cyberleninka.ru/article/n/o-mehanizmah-sotsialnoy-zaschity-naseleniya-vrespublike-kazahstan

4. Ламперт, Хайнц. Социальная рыночная экономика. Германский путь: [Пер. с нем.] / Хайнц Ламперт. - М.: Дело, 1993. - 220, [4] с.; 20 см.; ISBN 5-85900-052-9: Б. ц.

5. Социальное обеспечение: вопросы, задачи и перспективы.- Доклад / Междунар. конф. труда, 89-я сес.МБТ - Женева. - 2001.- с.53

6. Циткилов П.Я. Система социальной защиты в Республике Казахстан» // Россия и современный мир, № 3.2014. - c. 23-28 https://www.elibrary.ru/item.asp?id=22137701

7. E.N. Valieva, S.Mashanova, R.R. Yarullin Social protection system development in Kazakhstan in the context of European trends. - PEDTR 2019 18th International Scientific Conference "Problems of Enterprise Development: Theory and Practice «European Proceedings of Social and Behavioral Sciences EpSBS.- e-ISSN: 2357-1330 https://doi.org/10.15405/epsbs(2357-1330).2020.4.1 